\title{
A study of a patient who had alexia without agraphi商
}

\author{
W. J. K. CUMMING ${ }^{1}$, L. J. HURWITZ ${ }^{2}$, AND N. T. PERL ${ }^{3}$ \\ From the Department of Neurology, City, Claremont Street and Royal Victoria Hospitals ${ }^{2}$, and the Departmen \\ of Anatomy ${ }^{1}$ and Mental Health (Clinical Psychology) ${ }^{3}$, The Queen's University, Belfast
}

Word blindness and an aphasic writing difficulty are found, not infrequently, when disease of the left occipital lobe has extended anteriorly into the parietal and temporal areas. A less common clinical phenomenon is word blindness with unimpaired writing. Geschwind (1965) analysed personal and previously reported patients and suggested as a cause a particular type of cerebral disconnection, which was in accord with the postulates of other authors. The anatomical basis for the clinical syndrome was given as lesions in the left (dominant) occipital lobe and the splenium of the corpus callosum with an intact left supramarginal gyrus. A clinical, psychological, and anatomical study is presented here which supports this localization.

\section{CASE REPORT}

W.L., a labourer, was aged 64 years at death. His illness began suddenly about 17 months before his death, when he complained of frontal headache, blurring of vision, and double vision. Within a few days of the onset, he commented that he was bumping into objects on the right of him. It was then that he noticed he could not read the newspaper, and reading difficulty was his main complaint when examined in detail in hospital 11 months before his death.

He had normal insight into his condition, but was rather lacking in spontaneous action and drive. He was fully orientated and showed no perseervation in simple actions. He was able to give the days of the week in order, both forwards and backwards, without difficulty. He gave the months of the year forwards, but in attempting to do this series backwards he appeared to work out the month by saying the months to himself in a forward direction until he reached the correct one. He could register a name and address and recall it partly after five minutes. He had a superficial knowledge of current events and showed no features of constructional apraxia. He could do simple calculations.

On neurological examination there was no anosmia. The fundi were normal. Visual acuity was $6 / 6$ in each eye. There was a right homonymous hemianopia which seemed to split the macular field. Eye movements were full. There was no hearing loss. Power, co-ordination, and sensation in all four limbs were unimpaired. Two- point discrimination was $4 \mathrm{~mm}$ at the pulp of the finge tips, tactile localization was good, and there was no extinction of simultaneous tactile stimuli. The tendofid reflexes were present and equal and the plantar reflexes. were both flexor. He showed a little swaying on Romp berg's test, but he could balance on one foot and walk heel to toe. On general examination there was soms cardiac enlargement clinically and his blood pressure was $170 / 110 \mathrm{~mm} \mathrm{Hg}$. He had some evidence of bronchitis and emphysema.

At his first admission, radiological examination of the skull and chest revealed no abnormality, a brain isotop $\vec{E}$ scan was normal and the serum Wasserman and Kaㅐ reactions were negative. There was no labora evidence of uraemia or diabetes.

EXAMINATION OF LANGUAGE FACULTY When fors seen he had no difficulty in naming sighted objegts His spontaneous talk was fluent and was withe dysphasic features. He could respond appropria底ly to auditory requests such as 'touch your left $6 a x$ with your right thumb'. He could not name letters or words that were written, nor had he any undero standing of written language. $\mathrm{He}$ could easils match letters and words presented visually. Whe given a letter that he could not name he attempteक to trace it out with his right index finger and afteo a few seconds he usually named it correctly. If given sufficient time-some minutes-he coul $\$$ respond appropriately to a simple written commande such as 'raise your arm' by tracing each letter wit his finger. He could name a plastic letter that he could not see if it were placed in either hand and he seemed to be able to do this equally well wit the left or the right hand. He never had any difficulty. in reading Arabic numerals. He could not read Roman numerals, but he said that he never haథ this facility. He had little difficulty in writing to dictation, but he could not read back what he had previously written, once the memory of it cease to operate. He could copy what he could not read but he tended to copy script in block capitals and had very great difficulty in switching from capital letters to script. He could write a smahu 
message spontaneously and grammatically. He had no difficulty in naming colours and he could sort and match colours normally.

FOLLOW-UP There was no change in the neurological signs throughout a six month period of close observation, beginning six months after the onset of his illness and ending five months before his death. In particular, the right homonymous hemianopia remained dense, and there was no change in his literal alexia without agraphia. However, be became less spontaneous in his actions and activities and more inclined to sit around when not stimulated. In the last few months of his life he had numerous attacks of left ventricular failure and ventricular arrhythmia which necessitated admission to a general hospital. He was seen a fewtimes in between these attacks and the features of alexia without agraphia remained, but it was noted that he had some difficulty in naming sighted objects, and that there was general dulling of the intellect. Even then he did not show any aphasia in his spontaneous speech or in his writing. Ten days before his death he suddenly developed a left hemiplegia. After some days in coma he died from bronchial pneumonia, pulmonary oedema, and congestive heart failure.

PSYCHOLOGICAL INVESTIGATION The results of standard psychometric procedures are given in Table 1.

TABLE 1

RESULTS OF STANDARD PSYCHOMETRIC PROCEDURES

\begin{tabular}{|c|c|c|c|}
\hline $\begin{array}{l}\text { Wechsler adult intelligence } \\
\text { scale (WAIS) } \\
\text { ( } 8 \text { subtests) }\end{array}$ & $\begin{array}{l}25 \text { September } \\
1967\end{array}$ & $\begin{array}{l}\text { Verbal IQ } \\
\text { Performance IQ } \\
\text { Full scale IQ }\end{array}$ & $\begin{array}{l}93 \\
68 \\
82\end{array}$ \\
\hline $\begin{array}{l}\text { Wechsler adult intelligence } \\
\text { scale (WAIS) } \\
\text { ( } 5 \text { subtests) }\end{array}$ & $\begin{array}{l}31 \text { January } \\
1968\end{array}$ & $\begin{array}{l}\text { Verbal IQ } \\
\text { Performance IQ } \\
\text { Full scale IQ }\end{array}$ & $\begin{array}{l}85 \\
65 \\
74\end{array}$ \\
\hline $\begin{array}{l}\text { Delayed visual recall } \\
\text { (Williams, 1968) }\end{array}$ & $\begin{array}{l}17 \text { October } \\
1967\end{array}$ & $\begin{array}{l}\text { Score: } 8 \\
\text { (normal range) }\end{array}$ & \\
\hline $\begin{array}{l}\text { Non-verbal learning } \\
\text { (Williams, 1968) }\end{array}$ & $\begin{array}{l}17 \text { October } \\
1967\end{array}$ & $\begin{array}{l}\text { Score: } 32 \\
\text { (very poor) }\end{array}$ & \\
\hline $\begin{array}{l}\text { Paired-associate learning } \\
\text { test (Inglis, 1959) }\end{array}$ & $\begin{array}{l}17 \text { October } \\
1967\end{array}$ & $\begin{array}{l}\text { Score: } 9 \\
\text { (normal range) }\end{array}$ & \\
\hline $\begin{array}{l}\text { Memory for designs } \\
\text { (Graham and Kendall, 1960) }\end{array}$ & $\begin{array}{l}17 \text { October } \\
1967\end{array}$ & $\begin{array}{l}\text { Raw score: } 5 \\
\text { (normal range) }\end{array}$ & \\
\hline
\end{tabular}

Although it was only possible to carry out some of the subtests of the WAIS, the scores he obtained were indicative of a low average intellectual capacity, in keeping with the patient's occupation and educational attainment. Tests of verbal learning and visual memory showed no defect in these abilities, although a poor score was obtained on a test of spatial learning (Williams, 1968). A simple test of tactile transfer was given, using four of the wire patterns from the 6PALT test (Meyer, 1959). The patient was blind- folded and a pattern was pressed into his right hand. He was allowed to palpate the pattern for about 10 seconds, then, as the first was removed, another pattern was put into the same hand. He was told 'this one goes with this one'. He was again allowed to palpate for about 10 seconds and the pattern was taken away. After another 10 seconds the process was repeated with another pair of patterns. He was given the original pattern to palpate and was asked to find which of the two 'second-in-pair' patterns went with the original. After each failure the correct pattern was placed in his hand. Using only his right hand, he learned the two pairs in 17 trials. He was then given the first pattern in his left hand, and had no difficulty in picking out the correct partner for this and the other 'first-in-pair' patterns. This demonstrated the preservation of some ability for tactile learning and tactile transfer.

Since the capacity for all types of interhemispheric transfer was of particular importance in this case, a further test was devised. Ten small familiar objects-for example, a pencil, a rubber, a coinwere shown to the patient, who was then blindfolded. He was asked to palpate one of the objects with one hand and then to select it visually, by pointing, from the array of 10 . The next object was presented to the other hand, and the procedure was repeated until all the objects had been palpated by both hands. He made no errors on this test, although he could not name two of the objects. The difficulty of the task was then increased and the possibility of verbal mediation reduced by replacing the familiar objects with 10 small radio parts, which he would not be able to name. The same procedure was followed and out of a total of 20 trials he made five errors with his left and three with his right hand.

There was, thus, no significant difference between his ability to recognize in his left visual field objects which had been palpated by his left and by his right hand. The use of unfamiliar objects, although it increased the difficulty of the task, did not elicit significant lateral differences in tactile-visual transfer. Another task was used to investigate visual-tactile transfer. A Gerbrand's 'Harvard' tachistoscope and cards bearing the capital letters $\mathbf{H ~ L ~ T ~ W ~ K ~ X ~}$ $\mathrm{Z}$ and $\mathrm{N}$, drawn in black ink approximately $\frac{1}{2}$ in. to the left of the fixation point were used. The patient was told that he would see some letters which he was not to attempt to name. He was required to trace the shape of the letter on the table with the forefinger of one hand. The letters were given at random and before each one was exposed he was told which hand to trace with. He understood these instructions and showed no confusion in hand use throughout the experiment. The first exposure 
of the letters was at $20 \mathrm{msec}$ and was lengthened by increments of $10 \mathrm{msec}$ until he made his attempt to trace. He always made a recognizable tracing at the first attempt, without looking at his hand. The results (Table 2) showed that the exposure times required for a left and a right hand trace did not differ significantly, although longer exposures were more often needed for right hand tracings. This showed that he could transfer visual information from the right hemisphere to the left motor cortex about as efficiently as he could to the right motor cortex, and that he was capable of reproducing a visual image in another modality.

TABLE 2

EXPOSURE TIMES NEEDED FOR CORRECT TRACING OF LETTERS WITH LEFT OR RIGHT HAND

\begin{tabular}{|c|c|c|c|}
\hline \multirow[t]{2}{*}{ Card no. } & \multirow[t]{2}{*}{$\begin{array}{l}\text { Letter in } \\
\text { left field }\end{array}$} & \multicolumn{2}{|c|}{$\begin{array}{l}\text { Exposure time (msec) for } \\
\text { correct tracing with }\end{array}$} \\
\hline & & Left hand & Right hand \\
\hline $\begin{array}{l}35 \\
50 \\
53 \\
61 \\
58 \\
70 \\
65 \\
81 \\
82 \\
84 \\
87 \\
92 \\
56\end{array}$ & $\begin{array}{l}\mathbf{H} \\
\mathbf{T} \\
\mathbf{X} \\
\mathbf{Z} \\
\mathbf{L} \\
\mathbf{V} \\
\mathbf{Z} \\
\mathbf{K} \\
\mathbf{X} \\
\mathbf{Z} \\
\mathbf{T} \\
\mathbf{N} \\
\mathbf{K}\end{array}$ & $\begin{array}{l}50 \\
50 \\
40 \\
40 \\
50 \\
40 \\
50 \\
50 \\
40 \\
50 \\
70 \\
60 \\
40\end{array}$ & $\begin{array}{l}50 \\
60 \\
60 \\
30 \\
50 \\
40 \\
50 \\
70 \\
70 \\
60 \\
70 \\
60 \\
60\end{array}$ \\
\hline
\end{tabular}

$P>0 \cdot 19$.

In order to obtain more information about the interhemispheric transfer of visual learning, the following experiment was undertaken. A device, a track tracer, consisting of a rotating roller on which an irregular track was drawn, was used. At the sides of the track were raised bare wire fences: the patient was told to try to keep a metal stylus on the track without touching the fence at the side. Although any error in performance results in auditory, tactile, and kinaesthetic stimulation as the automatic counter clicks and the stylus rebounds from the side of the track, most of the input from the apparatus is visual. The patient was given one trial with his right hand, followed by 10 trials alternating between right and left hands. One trial was one complete circuit of the track, which took 75 seconds. The patient was given one second's rest between trials. This test (Fig. 1) showed that he made fewer errors with his left hand than with his right. Comparing trials $2,4,6$, 8 , and 10 (right hand) with trials $3,5,7,9,11$ (left hand) statistically, using a sign test (Siegel 1956),

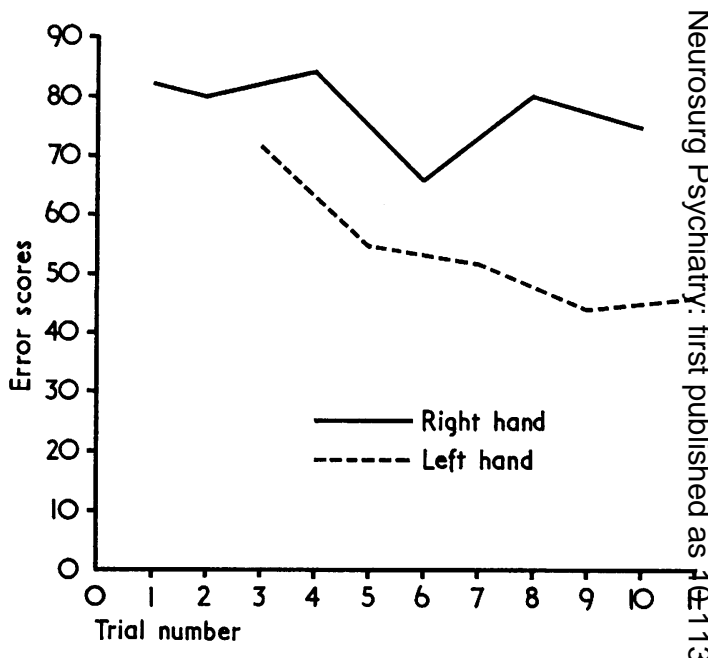

FIG. 1. Error scores on track tracer task. The left hat error scores become significantly lower with practice.

shows that the left hand error scores were significantly lower $(P<0.03)$, despite the fact that ${ }^{2} h_{s}$ right hand had one more trial's practice. The sine experiment was performed with a normal subtrect and with right-handed patients with right and hemianopia. Our patient was the only one to pe? form consistently better with his left hand ongh task. Since all visual input was to his right he sphere, the results suggest that he found visigi motor interhemispheric transfer difficult.

ANATOMICAL STUDIES Necropsy was carried ot on this patient within 24 hours of his death, by Dr. Ingrid Allen.

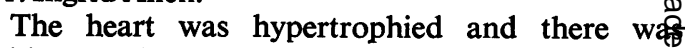
evidence of atheroma of the coronary vessels, with old and recent infarcts. The lungs and trachea showed evidence of bronchitis and a patchy broncho pneumonia. The brain weight $(1,500 \mathrm{~g})$ was withi normal limits. Focal atheroma of the major cerebral arteries was seen and there was an extensive infarct of the left occipital lobe (Fig. 2). There was a recen infarct of the right temporo-parietal region (Fig. 39 but there was no naked-eye evidence of infarction elsewhere in the brain. There was no microscopio evidence of infarction in four randomly selected blocks of cerebral tissue.

The circle of Willis showed as anatomical mah formation with the right posterior cerebral arter. retaining its embryonic derivation-a direct branc $\bar{b}$ of the right internal carotid artery.

The brain was cut into several coronal slices ant the portion of the corpus callosum, $1 \mathrm{~cm}$ on eithe 


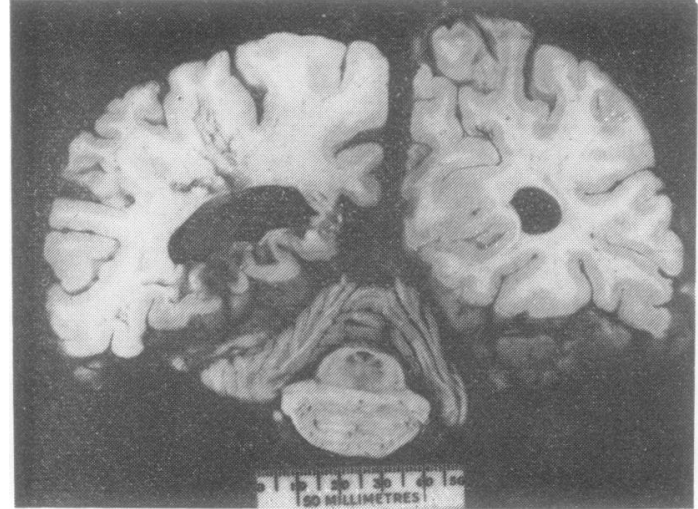

FIG. 2. Patient's brain in coronal section to show infarction of left occipital lobe.

side of the mid-line, was removed. It was noticed than the region of the splenium was much more friable that the more anterior parts.

HISTOLOGY OF THE CORPUS CALLOSUM The corpus callosum of the brains of four cases (aged 62 to 64 years) who had died after acute myocardial infarction and in whom there had been no neurological symptoms present during life were also examined as control material. The tissues were processed together to ensure uniformity. The sections were stained by the Glees-Marsland method for axons and by the Volkes method, which only displays normal myelin.

In the myelin stained sections (Fig. 4a, b), it can be seen that there is extensive demyelination of the posterior part of the corpus callosum. However,

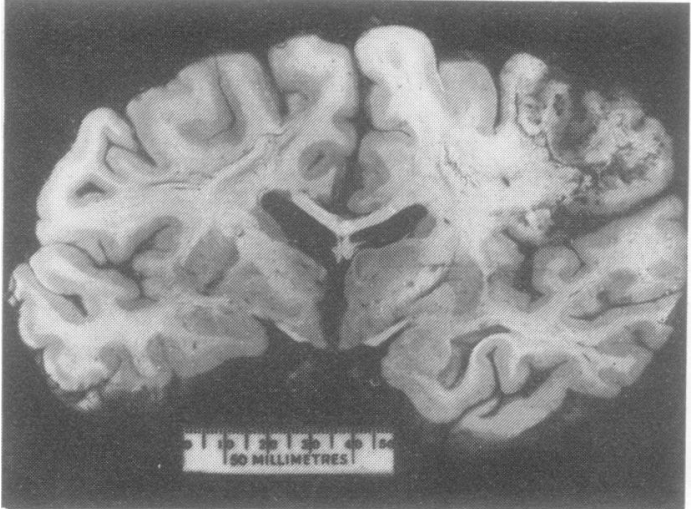

FIG. 3. Patient's brain in coronal section to show infarction in right temporo-parietal region.

there is a rim of intact nerve fibres in the dorsal part of the splenium (Fig. 4b). The area of demyelinization was $1.7 \mathrm{~cm}$. Therefore the area involved represented approximately a fifth of the callosal length. The site of the corpus callosum lesion involved in the 68-year-old patient of Dejerine (1892), on whom necropsy was performed by Vialet (1893), was given as the posterior $1 \mathrm{~cm}$. In a personal series of one of us (W.J.K.C.), the mean callosal length in 20 brains in the age range 55 to 69 years was $8.0 \mathrm{~cm}$. The patient of Dejerine had, therefore, involvement of about one eighth of the corpus callosum and between a quarter and one fifth in our patient.

In the sections stained for axons by the GleesMarsland method, it can be seen (Fig. 5a and b) that there is a great decrease in the total number of

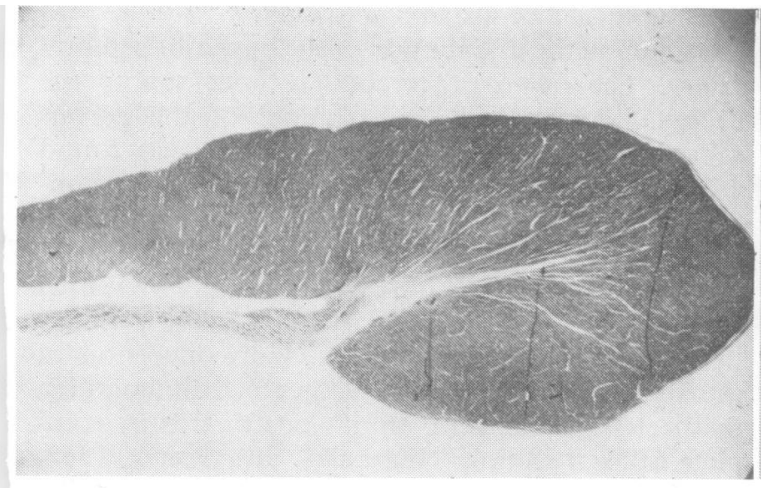

(a)

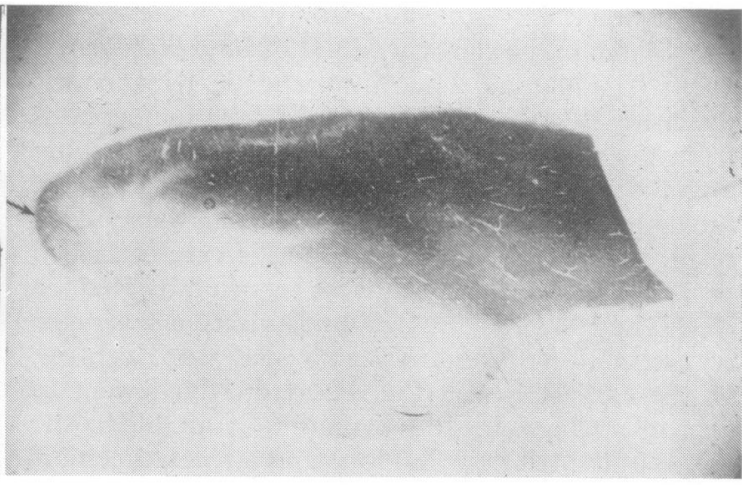

(b)

FIG. 4. Section including splenium of corpus callosum: (a) control brain, and (b) showing extent of infarction in patient's brain. Arrow indicates rim of intact nerve fibres. Volkes stain, $\times 1$. 


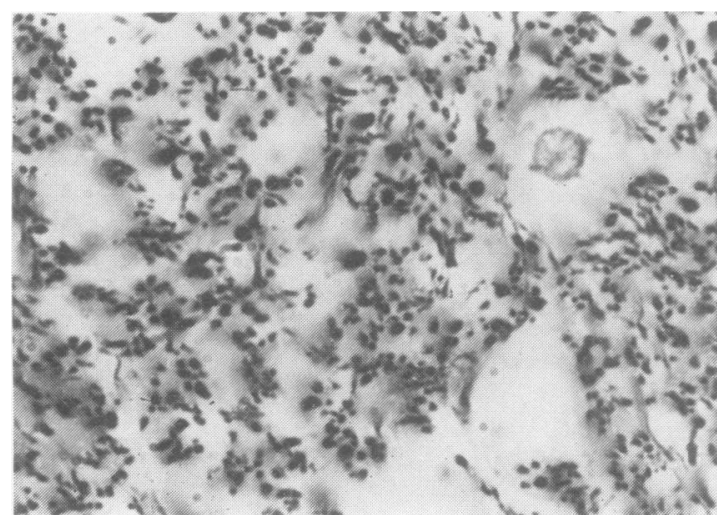

(a)
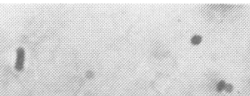

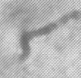

9

$\cdot$

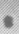

(2)

(b)

FIG. 5. Section of splenium: (a) control brain, (b) patient's brain. There is great loss of nerve fibres, but relative increase $\overrightarrow{0}$ in glial cells. Glees-Marsland stain, $\times 800$.

fibres present. The regions shown are from the infarcted brain and from a comparable area of a normal brain. In the four normal brains there was an average of $1 \times 10^{6}$ fibres/sq. $\mathrm{cm}$, whereas in the infarcted brain the number of fibres was 200/ sq. $\mathrm{cm}$. It can also be seen from Fig. $5 \mathrm{~b}$ that there is a relative increase in the number of glial cells present.

\section{DISCUSSION}

Two basic assumptions are necessary. The first is that all visual stimuli were received in the right occipital lobe of the patient. The second is that in the patient, who was strongly right handed, the left cerebral hemisphere was dominant for verbal symbols. The manner by which the literal dyslexia is associated with an intact ability to write can be formulated in the classical way (Foix and Hillemand, 1925; Alajouanine, Lhermitte, and de RibaucourtDucarne, 1960; Geschwind, 1965)-the connections from the right occipital cortex to the word finding area in the left hemisphere which pass through the splenium of the corpus callosum have been severed. Bastian (1897) discussed the case aescribed by Dejerine (1892) and patients reported by Redlich (1895) and Wyllie (1894) and postulated a severance of association fibres between visual word centres. In the earliest case to be reported, which went to necropsy (Landolt, 1888), there was an old cystic lesion in the left occipital lobe and a recent haemorrhagic lesion in the corpus callosum. The fluency of writing indicates that the left supramarginal gyrus is intact, while the ability to name letters that had been manually palpated by the patient's left hand indicates integrity of the anterior part of the corpus callosum. These essential anatomical stipulations for the syndrome of alexia without agraphia arefulfilled in the patient described here. The destructigniw of all but a rim of fibres in the splenium of the corptiso callosum cannot be due to transneuronal degene? tion after total infarction of the left occipital cortex, because fibres crossing from the intact right occipin $\mathbb{B}$ lobe were deficient also. The fibre counting showsde a relatively abrupt line of demarcation betwe the damaged posterior and the intact anter. $\mathrm{r}-$ four-fifths of the corpus callosum. This is in keeping with a vascular lesion and it is noteworthy that at necropsy a congenital anomaly of the righto posterior cerebral artery of a type commonly des-s cribed (Battacharji, Hutchinson, and McCall, 1967)ō was found. Alpers and Berry (1963) have reportedoै a $29 \%$ incidence of this anomaly in brains with infarction in the distribution of the posterior cerebraf artery. The posterior cerebral arteries supply the occipital cortex and the splenium of the corpus? callosum, and, although no occlusion was found? at necropsy, the combination of atheroma, con genital anomaly, and myocardial embarrassmento would be sufficient to produce infarction.

The preserved ability to name visually presented objects, but not letters or words, is a major obstacle in accepting the hypothesis of a disconnection of the right visual cortex from the word finding areas in the left hemisphere. In patients treated by com-? plete callosal section (Gazzaniga and Sperry, 1967) the ability to name sighted objects presented by tachistoscopy in the left half field was absent. Yeto in all the patients who have been described as having dyslexia without agraphia this faculty has 
been intact. Geschwind (1965) has postulated that objects, but not letters, have tactile, auditory, and olfactory associations which enable intrahemisphere connections to operate and consequently interhemisphere connections through an intact part of the corpus callosum. Towards the end of our patient's illness there was some difficulty in naming sighted objects. At the time it was considered that general neuronal loss and perhaps a small lesion in another area of the left cerebral hemisphere were responsible. However, at necropsy there was no obvious involvement of the left hemisphere, apart from the occipital lobe. The recent infarct in the right cerebral hemisphere would account for the left hemiplegia noted 10 days before death.

A colour naming difficulty is frequently found in patients with alexia without agraphia (Geschwind and Fusillo, 1966; Gloning, Gloning, Jellinger, and Tschabitscher, 1966) and these authors review the literature. Our patient did not have any difficulty in naming or matching colours during the period of close observation. Of possible significance in our patient was the finding of a small rim of intact nerve fibres in the splenium, but it is conjecture as to whether this could have any bearing on the naming of colours and of objects but not letters.

During life, normal tactile interhemispheric transfer was demonstrated. Some evidence of impairment of interhemispheric visual learning transfer was found, but the results obtained could have been greatly influenced by even a slight weakness or other impaired functioning of the right upper limb. However, clinical examination had not revealed any abnormality in this limb.

\section{SUMMARY}

A clinical, psychological, and anatomical study is presented of a man aged 64 , who had alexia without agraphia. Infarction of the left occipital lobe and the splenium of the corpus callosum were found. The clinical and psychological findings are discussed in relation to the pathological lesions.

We are grateful to Dr. T. J. Harrison and Dr. Ingrid Allen of the Departments of Anatomy and Pathology, of the Queen's University, Belfast, for their advice, and to Dr. J. Barber for his help.

\section{REFERENCES}

Alajouanine, Th., Lhermitte, F., and de Ribaucourt-Ducarne, B (1960). Les Alexies Agnosiques et Aphasiques, pp. 235-260 in Les Grandes Activites du Lobe Occipital. Edited by Th. Alajouanine. Masson et Cie: Paris.

Alpers, B. J., and Berry, R. G. (1963). Circle of Willis in cerebral vascular disorders. Arch. Neurol. (Chic.), 8, 398-402.

Bastian, H. C. (1897). Some problems in connexion with aphasia and other speech defects. Lancet, 1, 1187-1194.

Battacharji, S. K., Hutchinson, E. C., and McCall, A. J. (1967). The Circle of Willis - the incidence of developmental abnormalities in normal and infarcted brains. Brain, 90, 747-758.

Dejerine, J. (1892). Contribution à l'étude anatomo-pathologique et clinique des différentes variétés de cécité verbale. $C . R$. (Mémoires) Soc. Biol., 4, 61-90.

Foix, C., and Hillemand, P. (1925). Rôle vraisemblable du splénium dans la pathogénie de l'alexie pure par lésion de la cérébrale postérieure (1). Bull. Mém. Soc. méd. Hop. Paris, 49, 393-395.

Gazzaniga, M. S., and Sperry, R. W. (1967). Language after section of the cerebral commissures. Brain, 90, 131-148.

Geschwind, N. (1965). Disconnexion syndrome in animals and man, Part 1. Ibid., 88, 237-294.

with alexia. Arch. Neurol. (Chic.), 15, 137-146.

Gloning, I., Gloning, K., Jellinger, K., and Tschabitscher, H. (1966) Zur dominanz-frage beim Syndrom: Reine Wortblind-heitFarbagnosie. Neuropsychologia, 4, 27-40.

Graham, F. K., and Kendall, B. S. (1960). Memory-for-Designs Test. Psychological Test Specialists: Missoula, Mont.

Inglis, J. (1959). A paired-associate learning test for use with elderly psychiatric patients. J. ment. Sci., 105, 440-443.

Landolt, E. (1888). De la cécité verbale. Neurol. Cbl., 7, 605-606.

Meyer, V. (1959). Cognitive changes following temporal lobectomy for relief of temporal lobe epilepsy. Arch. Neurol. Psychiat. (Chic.), 81, 299-309.

Redlich, E. (1895). Uber die sogenannte subcorticale Alexie. Jahrb. Psychiat., 13, 243-302.

Siegel, S. (1956). Non-parametric Statistics for the Behavioral Sciences. McGraw-Hill: New York.

Vialet, N. (1893). Les Centres Cérébraux de la Vision, et l'Appareil Nerveux Visuel Intracérébral. Thèse: Paris.

Williams, M. (1968). The measurement of memory in clinical practice. Brit. J. Soc. clin. Psychol., 7, 19-34.

Wyllie, J. (1894). The Disorders of Speech, Oliver \& Boyd: Edinburgh. 